Original Article

\title{
On the role of natural science methods in the investigation of low doses effects
}

\author{
N. Ampilova ${ }^{1 *}$, I. Soloviev $^{1^{* *}}$, E. Gurevich ${ }^{2}$ \\ 1 St. Petersburg State University, St. Petersburg. E-mail: *n.ampilova@spbu.ru, **i.soloviev@spbu.ru 2 Organic Product Ltd., St. Petersburg info@organicproduct.ru
}

\begin{abstract}
Background: Modern achievements of physics, biology, chemistry, mathematics and informatics considerably extend scientific basis for explanation of low doses effects in homoeopathy. The research of many great scientists has made it feasible to create a physical model describing this effect [1-5]. Now experimental investigations based on the methods of natural sciences allows us to register the dynamics of processes in biological systems. The results may be represented by various ways, in particular as digital images or signals. The application of mathematical and computer methods of image analysis opens up possibilities to obtain numerical data that characterize real processes and helps to estimate the biological system state, which is important in medical practice $[6,7]$.

Aims: To obtain numerical characteristics of biomedical pr

ration images.

Methodology: Application of mathematical and computer methods for image analysis in biology and medicine.

Results and discussion: We apply image-analysis to study hanges in a biological system state. Our experiments on some classes of biomedical preparations including ones obtained by sensitive crystallization and capillary dynamolysis phthopds resul res in obtaining numerical characteristics which allows us to distinct images from differen asses (kuch as acute and chronic inflammatory processes, benign and malignant tumors, etc.) and may be considered as classifying signs.
\end{abstract}

Conclusion: The application of various mathematical and computer methods of images analysis results in classifying biomedical preparations and may be successfully used in medical practice.

\section{References}

1. A. Szent-Gyorgyi. Bioenergetics. Acad. Press, N.-Y., 1957.

2. E. Del Giudice, V. Elia, A. Tedeschi. Role of water in the living organisms. Neural Network World 19 (4), 2009, p. 355-360.

3. G. Ling. Life at the cell and below-

cell level. The hidden history of a fundamental revolution in biology. Pacific Press, N.-Y., 2001.

4. C. Mahata. Qantum electrodynamics helps homoeopathy achieve its scientific basis (paving the way for a generalized concept of medicine). Int. J. of High Dilution Research 2017; 16 (2), p. 5-10. 
5. L. Gall. Bioenergetics - the magic of life. St. Petersburg, 2010. (in Russian)

6. N. Ampilova, E. Gurevich, I. Soloviev I. Application of Modified Fractal Signature and Regny Spectrum Methods to the Analysis of Biomedical Preparations
Images. Proc. 6 Int. Conf. CEMA11, Sofia, Bulgaria, Oct. 6-8, 2011, p. 96-100.

7. N. Ampilova, I. Soloviev. Fractal analysis methods in investigation of ultralow doses effects. Proc. 12 Int. Conf. CEMA17, Sofia, Bulgaria Oct.12-14, 2017, p. 10-14.

Received: March 1, 2018. Accepted: April 26, 2018.

(C) International Journal of High Dilution Research.

Not for commercial purposes. 